\title{
Tissue engineering for intervertebral disc degeneration
}

Victor YL Leung, $\mathrm{PhD}{ }^{1}$, Vivian Tam, $\mathrm{PhD}{ }^{1}$, Danny Chan, $\mathrm{PhD}{ }^{2}$, Barbara P Chan, $\mathrm{PhD}^{3}$, Kenneth MC Cheung, MD ${ }^{1}$

1 Department of Orthopaedics \& Traumatology, The University of Hong Kong, Hong Kong SAR, China

2 Department of Biochemistry, The University of Hong Kong, Hong Kong SAR, China

3 Tissue Engineering Laboratory, Department of Mechanical Engineering, The University of Hong Kong, Hong Kong SAR, China

\section{Corresponding author:}

Prof. Kenneth MC Cheung

Department of Orthopedics and Traumatology, The University of Hong Kong

Medical Centre, Queen Mary Hospital, Pokfulam Road, Hong Kong

Tel. No.: (852) 28554254

Fax No.: (852) 28174392

e-mail: cheungmc@hku.hk

\section{Keywords:}

Intervertebral disc, degeneration, tissue engineering 


\begin{abstract}
Intervertebral disc engineering confronts many challenges owing to its complexity and the presence of extraordinary stresses. However, rebuilding a disc of native function could be useful for the removal of the symptoms, and the correction of altered spine kinematics that are associated with disc degeneration. Improvement in the understanding of disc properties and techniques for its engineering brings promise to the fabrication of a functional motion segment for the treatment of disc degeneration. While whole disc engineering is premature relative to articular cartilage engineering, the increasing sophistication of techniques available in biomedical sciences will eventually bring its application into clinics. In this review we give an account of the current progress and challenges of intervertebral disc bioengineering, and discuss possible means to move forward and towards bedside translation.
\end{abstract}




\section{Introduction}

Disease conditions are often manifested with the disruption of tissue structure and function, in which the body is incapable of repairing. Advancement in various disciplines including cell biology, developmental genetics, materials science, and biomechanics, has brought the realization that tissue engineering could assist tissue repair or replacement. Unlike cartilage engineering, the engineering of the intervertebral disc (IVD) confronts many challenges owing to its complexity and presence of extraordinary stresses related to its architecture and function. The IVD plays a crucial role in articulation of the spinal column and contributes to various body postures and force coordination in daily activities. Along with its role in articulation, the IVD has a major function in providing cushioning effects to the spine against axial load. As a result of the intensive mechanical stress, the IVD suffers from degeneration in a similar fashion to articular cartilage in loaded appendicular joints. The causes of IVD degeneration are not clear, although it is thought to be multifactorial with a large contribution from both genetic and environmental components [1,2], and may share common biological components exhibited in osteoarthritis [3]. Current treatments predominantly aim not to correct the degeneration, but alleviate symptoms such as back pain and sciatica which are often manifested by severe IVD degeneration or radiculopathy caused by prolapse of the degenerated disc. Conventional modalities range from surgical means such as spinal segment fusion, laminectomy, and total disc/nucleus replacement, to non-invasive physiotherapies such as ultrasound electrotherapy and traction.

Current theory suggests that when the IVD is degenerated, the articular unit has compromised mechanical function and subsequently, the motion segment becomes unstable under load. Consequently, this may result in significant pain and 
neurological irritations that can cause a severe decrease in daily activities of the individual. While intervertebral fusion, the 'gold standard' for treating symptomatic disc degeneration may stabilize the segment and relieve symptoms, juxtalevel degeneration may occur due to the observed hypermobility of the IVD adjacent to the fused segment [4]. Rebuilding an IVD of native function that allows appropriate interplay with other motion segment components including the facet joints and ligaments, could therefore be promising in the removal of symptoms whilst simultaneously reestablishing spine kinematics. A recent study of IVD allograft transplantation to treat cervical disc herniation in humans supports this notion [5]. Whilst total disc replacement may potentially resolve the issue in a similar manner, long-term results suggest that artificial disc replacements frequently result in spontaneous fusion, and is considered to be an expensive spacer for fusion [6]. Bioengineering of the IVD may therefore provide an alternative solution to address the issue.

Tissue engineering can be achieved at different levels of complexity, from cell programming and scaffold modeling, to cell-scaffold composite construction and multi-scale tissue fabrication. Advances in our understanding of IVD properties and techniques in its engineering at each of the levels may impact on the success of building a functional motion segment for treating disc degeneration. In this review, we give an account of the progress and challenges of IVD engineering, and propose what is needed to move forward and towards bedside translation.

\section{Disc cell engineering}

The IVD is composed of multiple subunits that integrate seamlessly to form sophisticated and complex mechanical function. It has three main structures: a 
gelatinous nucleus pulposus (NP) core wrapped around and confined by a fibrous lamella structure, the annular fibrosus (AF), and cartilaginous endplates (CEP) of the vertebrae sandwiching the NP and AF. The three compartments are different in mechanical properties and are functionally dependent on each other. These compartments are made up of various matrix components, predominantly collagens and proteoglycans, and comprise of different cells that are thought to play roles in maintaining the matrix integrity. From a developmental point of view, IVD formation involves the diversification of cells from a primitive anlage consisting of the notochord and its surrounding mesenchymal cells, a process that involves vigorous cell differentiation during the embryonic stage, and continual postnatal remodeling of its microenvironment including the extracellular matrices $[7,8,9]$.

The primary role of the IVD is to provide mechanical support and motion, which is largely attributed to the viscoelastic properties (the viscous and elastic behavior under deformation) of the IVD [10]. IVD-like properties and function may possibly be obtained by simply using acellular scaffolds or devices. However, materials with desirable viscoelastic properties pertaining to IVD are often biodegradable and therefore their function may not be sustained in the long-term. Cell-containing constructs are advantageous with cells enable to remodel the scaffold template, thereby maintaining or enhancing matrix integrity. More importantly, IVD transplantation studies have demonstrated the integration of disc allograft to recipient vertebrae by biological remodeling at the endplates, including that of mis-aligned discs which were also found to self-correct post surgery [5]. Since the self-correction is considered to eventually contribute to motion segment kinematics and stability in the long term, cellular IVD constructs would theoretically outperform acellular prosthetic devices in function. 
The loss of integrity and viscoelasticity of the NP is one of the earliest observable events in disc degeneration, suggesting that the engineering of the NP is crucial to the success of a functional IVD construct. Considerable effort has been invested into understanding the NP, in particular, delineating the NP cell phenotype so as to facilitate NP cell engineering for the creation of cellular IVD constructs. Two cell populations are thought to exist in the NP: small non-vacuolated cells with a chondrocyte-like phenotype, and large vacuolated cells which are often referred to as notochordal cells [11]. The large vacuolated NP cells have been shown to originate from the notochord [8], whereas controversy still surrounds the origin of the chondrocyte-like cells, particularly in human NP. Nevertheless, recent studies have provided some insights to the molecular identity of the latter type of cells based on microarray-based gene expression profiles of NP cells from adult human [12], bovine [13], and chondrodystrophoid dog [14]. Notably, these studies did not yield common genetic markers that is translatable among different species, but rather, indicated the presence of species-specific markers, for example $P A X 1$ and FOXF1 in human, $A 2 m$ and Anxa4 in canine, and Snap25 and Krt8 in bovine. Expression profile studies of rodent NP cells [15], which predominantly consist of large vacuolated notochordal cells, also suggested that markers may not be shared with human NP cells, and indicated that notochordal and chondrocyte-like NP cells may be distinct in phenotypes. This is supported by cell sorting studies in which the two populations were separately extracted from the same animal for comparative analyses $[13,16]$. Nevertheless, recent studies suggest that a crosstalk may possibly exist between the two cell populations, complicating the search of the true NP cell identity [17][18].

IVD and articular cartilage have different mechanical properties. The transplantation 
of chondrocyte-like cells or the use of such cells in the engineering of NP constructs may not produce a disc with ideal function. On the other hand, future IVD engineering will likely utilize stem cells and other progenitor cell types to differentiate into NP cells and generate them in large quantity. Unless the phenotype and the functional characteristics of the notochordal and chondrocyte-like NP cell types are clearly defined, the generation of authentic NP cells from stem/progenitor cells and hence bioengineering of NP with native mechanical properties may not be achieved. In vitro studies have suggested that stimulation by co-culturing with NP cells $[20,21,22,23]$, induction of chondrogenic transcription factor SOX9 [24,25] or stimulation by chondrogenic growth factors TGF- $\beta 1$ (transforming growth factor beta 1) $[25,26,27]$ are attractive strategies to drive differentiation of adult stem cells, such as mesenchymal stem cells, into NP-like cells. However, whether or not the differentiated cells have attained an authentic NP cell or chondrocyte-like phenotype remains elusive. Engineering the NP with chondrocytes is not desirable since it is likely that the construct will become hyaline cartilage instead of NP tissue and hence possesses inappropriate viscoelastic properties.

AF cells are generally referred to as fibrochondrocytes. This phenotype is based on the ability of AF cells to produce collagen I and III, in addition to collagen II and aggrecan which are produced to a lower extent [28]. Compared to NP cells, the molecular phenotype of AF cells and their changes in disc degeneration is less clear. While NP and AF are morphologically different and supposedly have different cell phenotypes, recent transcription profiling studies indicated that AF cells express a large number of non-house-keeping genes at similar level to that of NP cells $[12,13,14]$. Nevertheless, other potential markers are suggested to be differentially expressed at higher levels in the AF relative to the NP, for example $V C A M 1$ in human 
[12]. Fibromodulin has been shown to be a specific marker of the AF in rodent [30], however, its expression pattern in humans or large animal models is unclear. On the other hand, while the CEP is assumed to be analogous to hyaline cartilage and consists of chondrocytes, the molecular phenotype of CEP cells is also not clear, and that there is a lack of evidence that demonstrates their similarities. In fact, histological findings have suggested that there is a difference in the glycosaminoglycan composition and collagen VI and $\mathrm{X}$ expression between CEP and growth plate cartilage [9,31]. It is not clear whether or not the use of chondrocytes in bioengineering can fully fulfill the function of the CEP.

\section{Engineering the disc microenvironment}

The bulk of the IVD is composed of extracellular matrix which plays prominent roles in the regulation of the disc cell environment and providing anchorage to disc cells. The extracellular matrix of the IVD, like cartilage, is comprised of mostly collagens which provide tensile strength of the disc [32], and proteoglycans, which function to reduce the internal friction in the disc matrix and to distribute load [33]. Importantly, they also account for the viscoelastic behavior of the IVD, contributing to the shock absorbing property [34]. Based on the relationship between function and form, materials that can mimic the anatomic architecture and mechanical properties of native IVD (reviewed by Nerurkar et al [10]) are of interest to disc bioengineers.

Like hyaline cartilage, aggrecan and collagen II are the two main extracellular matrix components of mature NP. Although the NP in mature human IVD is thought to be analogous to articular cartilage, the nature of the matrix and hence their mechanical properties are not exactly the same [35]. NP in young individuals have a high proteoglycan to collagen content, with a suggested GAG to hydroxyproline ratio of 
$27: 1$, in comparison to a $2: 1$ ratio in hyaline cartilage [36]. The high proteoglycan content in the NP matrix facilitates the retainment of water which attributes to the high hydrostatic pressure exhibited in the NP. Hydrogel scaffolds have been commonly used with the intention of simulating the NP microenvironment and entrapment of the newly deposited proteoglycan to facilitate the establishment of hydrostatic pressure. The effectiveness of various hydrogel-based scaffolds, either made from natural hydrophilic biomolecules or synthetic polymers, for NP engineering or repair has been documented. To date, alginate is one of most commonly adopted hydrogel scaffolds for NP cell culturing $[37,38]$ due to its ease of manipulation, biodegradability and inert bioactivities. Hyaluronic acid (HA) has been used for the treatment of osteoarthritic knee joints via the direct application into the synovial cavity, and in vivo studies propose that HA $[39,40,41,42]$ or HA-derived hydrogel $[43,44,45]$ may facilitate NP function and promote motion segment mechanics. However, because the NP plays an important role in withstanding the compressive load so as to maintain disc height and range of motion of spinal segment, pure hydrogel scaffolds, which lack confined compressive strength, may not be adequate for NP engineering. Collagen I microspheres [46,47] and calcium polyphosphate [48] may on the other hand provide good tensile and compressive strength to support stem cells or NP cells in NP engineering. Recent studies have focused on the generation of collagen-incorporated [50,51,52] or polymer-linked $[53,54]$ hydrogels. These hybrid scaffolds mimic the native microenvironment of the NP to reproduce its viscoelastic and load distribution behavior within the IVD. In fact, while swelling is known to provide the main load-bearing mechanism in the NP, the extensive collagen network inside the disc has also been suggested to support a considerable portion of load as the collagen fibril meshwork contributes to the compressive modulus to the tissue [55]. Moreover, collagens have been shown to act 
as a reservoir of signaling ligands, such as TGF- $\beta 1$ and BMP-2 for collagen II [56], and are able to transduce mechanical signals [57,58], therefore serving as important regulators of cell function and homeostasis.

In addition to NP engineering, current research has attempted to use injectable scaffolds as carriers to deliver cells with the aim of salvaging disc degeneration or on its own, as fillers for NP replacement using a minimally invasive approach [52]. Studies have also developed injectable materials that have the ability to self-assemble into a higher-order network, resulting in a sol-gel (solution-to-gel) transition. For example, atelocollagen (pepsin-digested collagen) can self-crosslink to form a fibrous meshwork $[59,60]$, and chitosan $[27,61]$ and synthetic peptides $[62,63,64]$ have been reported to self-assemble into a nanofiber network. Other natural biomolecules including hyaluronan and chitosan, when modified with crosslinkable moieties, are capable of chain polymerization through photochemical reactions [65]. These materials, as injectable media, may deliver cells of interest by providing a transient framework that prevents leakage of implants and allow for the accumulation of the extracellular matrix deposited by the introduced cells.

While intradiscal pressure exerted by the NP plays an important role in disc function, it critically depends on the integrity of the AF. In addition, the trans-AF delivery system remains the commonly used way to manipulate the NP in clinical and experimental settings. The construction of AF may facilitate the repair of prolapsed discs and supplement nucleus replacement. Annulus closure devices [66] may possibly provide an effective means to treat prolapsed discs, however, may restrict segment motion and possibly modify the load distribution in the IVD. AF construction is understandably indispensable to IVD engineering, but effective 
bioengineering of AF may not be implemented without proper understanding of its microstructure and mechanics.

The AF lamellae are mainly composed of collagen I fiber bundles and have anisotropic mechanical behavior [67]. These bundles are approximately concentric to the lamellae around the NP, where the direction of alignment in one lamella differs to the next by $30^{\circ}[68]$. This angle-ply architecture of lamellae is thought to be designed to resist shear resulting from complex physiological stresses such as a combination of axial loading and torsion $[69,70]$. Annulus fibers are interconnected via intra-lamellar cross-bridges [71] and inter-lamellar bridges [72,73]. In vitro studies showed that excess circumferential constraint may negatively impact on NP cell metabolic activities [75], which suggests that tissue rigidity needs to be carefully controlled during AF construction. The rigidity of the AF largely depends on the mechanical properties of the materials used during fabrication. Various materials have been tested for AF tissue construction, and include porous silk [76,77], polymer nanofibers $[40,69,78,79]$, polylactide/Bioglass composite [80], and alginate/chitosan composite [81]. These scaffolds provide a framework of desirable mechanical and bioinductive properties for future AF engineering. An alternative is collagen gel $[82,83]$ or collagen-GAG composite [84], although fabrication into a specific geometry (such as fibers or lamella) or characteristic topographical template may be limited. Since AF cells are normally aligned with the lamella fibers, it may be ideal that AF constructs can be engineered through simultaneous controlled placement of AF cells and orientation of the matrix they interact with, such as using scaffolds with specifically designed micro-grooves [85].

Collagen fiber structure determines the mechanical strength and elasticity of the 
annulus. Recent studies in AF engineering have shed light on some important aspects of its structural properties at the molecular level. Nerurkar et al showed that, through electrospun nanofiber fabrication, a bi-lamellar tissue model with AF-like angle-ply architecture can be generated $[70,86]$. By mechanical testing and modeling, they demonstrated that the bonding between the angle-ply lamellae is crucial to the resistance of inter-lamellar matrix to local deformations and therefore functions to reinforce the overall tensile response of $\mathrm{AF}$ architecture. Moreover, an in vitro study indicated that fibronectin can play a pivotal role in facilitating AF cell attachment and alignment on nanofibers [87], implying that a synergy between collagen and other non-collagen matrix components may be required to provide AF cells a niche to attain appropriate activities. Altogether, these findings indicate that the AF structure is not just a multi-layered fibrous tissue, but built with a sophisticated hierarchy of intraand inter-lamellar supramolecular interactions.

The CEP is involved in attachment of both AF and NP fibers [88]. Using a triphasic model, Kandel et al also suggested that the CEP is a critical interface for bone-disc integration by providing an adhesive force that is resilient to shear loading [89]. In addition, they reported that the CEP may secret factors to stimulate proteoglycan and inhibit TNF- $\alpha$ production in NP cells, suggesting CEP has a role in regulating NP homeostasis [90]. The CEP is thought to be similar to articular cartilage, and can be artificially engineered by plating and incubating chondrocytes at a high density on the target interface where they secret matrices to model the interface into a cartilage layer $[89,91]$.

\section{Towards whole disc engineering}

By the time a degenerated disc becomes clinically symptomatic and requires 
treatment, the $\mathrm{AF}$ and endplate, in addition to NP, are also structurally altered or functionally incompetent. In fact, at a severely degenerated stage, the motion segment is often largely compromised not only because of malfunction of the disc but also due to secondary arthritic changes such as facet joint degeneration and osteophyte formation. Transplantation of whole IVD appears to be a rational approach to replace severely degenerated spinal motion segments. This has been demonstrated recently in large animal models and in humans, where the transplantation of disc allografts was able to alleviate symptoms caused by the degenerated segment and thus a feasible option for treating disc degeneration [5,97]. However, it is still not clear if allografts may be routinely applied in practice due to the limited availability of non-degenerated disc tissue from healthy donors, and legislative regulations in utilizing human cadavers. Artificial disc installation may provide an alternative to overcome the issues. However, the application of artificial disc replacements may need to overcome additional hurdles such as recipient-graft integration and demand in surgical precision that could possibly be overcome using organic disc grafts due to their biological remodeling capacity [5].

While de novo bottom-up assembly of whole IVD is considered a challenging task, various attempts have been made to construct disc tissue prototypes with multi-compartmental features. Nesti et al [40] studied a biphasic model composing of an outer fibrous shell fabricated by electrospun nanofibers and an inner filling made of HA. Under stimulation with TGF, mesenchymal stem cells (MSCs) pre-implanted in the two compartments were able to differentiate, transforming the composite into AF- and NP-like structures. Mizuno et al [98] were able to produce an IVD-like tissue by generating a composite of AF cell-seeded synthetic polymer mesh wrapping around an NP cell-seeded alginate filling, which was subsequently implanted 
subcutaneously for in vivo modeling and resulted in a collagen/proteoglycan-rich construct of enhanced mechanical properties. Another study by Wan et al [99] tested the fabrication of a dual-layer composite consisting of bone matrix gelatin in one phase and chondrocyte-seeded, concentrically oriented polymer in another to replicate the inner and outer AF. Hamilton et al [89] constructed a triphasic model to recapitulate the bone-CEP-NP organization. With the fabrication technique that replicates the angle-ply fiber organization of AF, Nerurkar et al engineered a biochemically and mechanically functional AF-NP composite with MSCs. Collectively, these studies reveal the possibility of artificially engineering discs which are similar anatomically and mechanically to the native disc, and thus have laid a valuable foundation for building a fully functional multi-scale disc composite for total disc replacement. Future efforts are anticipated to build a complete CEP-NP-AF architecture in order to simulate the higher-order complexity of native disc tissues. An osteochondral interface with proper zonal organization between vertebre and CEP may also need to be carefully engineered to obtain satisfactory structural and functional complexity, such as via a collagen microencapsulation-based multi-layer co-culture method [100].

\section{Hurdles and perspectives}

The function of the IVD relies on an integrated dynamic interaction between the NP, AF and CEP. Therefore, de novo engineering of IVD would ultimately entail comprehensive knowledge in the biology and engineering techniques. At this stage, while the mechanical properties and functions of the individual compartments (i.e. NP, AF and CEP) have been fairly well studied, there is limited understanding in the interaction among the compartments. For instance, what components are present in the interface between NP and inner AF, and how AF/NP fibers are attached to the 
CEP. This is analogous to the interface between tendon and bone, but with more complex mechanical moduli due to interplay among the disc compartments.

Moreover, disc cell engineering appears to be one of the main hurdles in the progress of IVD bioengineering. This could be partly due to an incomplete understanding of their phenotypes and their modulation during disc development and homeostasis. Studies of animal and ex vivo culture models, such as transgenic mice and bioreactor systems, may provide clues, such as specific genes or signaling factors, necessary for the induction of progenitors or stem cells to become disc-related cell types, and to stably maintain the phenotype/characteristics of the derived cells in vitro. On the other hand, a better modeling of IVD microarchitecture may be achieved through molecular imaging and nanotechnology for better scaffold design and fabrication.

The engineering of a complete IVD is the first step of many, but the true challenge lies in the production of a fully functional IVD. Within a decade, we will probably arrive at a stage that will enable complete bioengineering of all disc compartments. However, in the long-term there may be a limitation in the available fabrication technology that enables the assembly of the building blocks to establish overall disc biomechanics. Perhaps to overcome the issue, one might possibly fabricate a disc anlage, a primitive construct composing of distinctly engineered compartments, and subsequently allow the construct (the so-called precursor tissue analog [103]) to evolve to form a mature IVD through native morphogenetic activities of disc cells, mimicking tissue growth and remodeling during the post-natal maturation process of the IVD [7,9]. Such a strategy may be realized with future advances in disc cell engineering and bioreactor systems for whole IVD culturing with mechanical stimulation $[63,95,104]$. Perhaps with advancement in tissue engineering and total 
disc replacement devices, it may be possible to combine both disciplines to create hybrid constructs with strengths in bioactivity, mechanical function, and durability.

Tissue engineering for IVD is at its infant stage when compared to articular cartilage engineering. However, in view of increasing the variety and sophistication of modalities available in cell biology, biomechanics, and tissue engineering, the bioengineering of whole functional IVD, and hence its clinical application, could eventuate in the not too distant future. 


\section{References}

1. Chan D, Song Y, Sham P, Cheung KM (2006) Genetics of disc degeneration. Eur Spine J 15 Suppl 15: 317-325.

2. Adams MA, Roughley PJ (2006) What is intervertebral disc degeneration, and what causes it? Spine 31: 2151-2161.

3. Loughlin J (2011) Knee osteoarthritis, lumbar-disc degeneration and developmental dysplasia of the hip - an emerging genetic overlap. Arthritis research \& therapy 13: 108 .

4. Samartzis D, Lubicky JP, Herman J, Kalluri P, Shen FH (2006) Symptomatic cervical disc herniation in a pediatric Klippel-Feil patient: the risk of neural injury associated with extensive congenitally fused vertebrae and a hypermobile segment. Spine 31: E335-338.

5. Ruan D, He Q, Ding Y, Hou L, Li J, et al. (2007) Intervertebral disc transplantation in the treatment of degenerative spine disease: a preliminary study. Lancet 369: 993-999.

6. Putzier M, Funk JF, Schneider SV, Gross C, Tohtz SW, et al. (2006) Charite total disc replacement--clinical and radiographical results after an average follow-up of 17 years. European spine journal : official publication of the European Spine Society, the European Spinal Deformity Society, and the European Section of the Cervical Spine Research Society 15: 183-195.

7. Dahia CL, Mahoney EJ, Durrani AA, Wylie C (2009) Postnatal growth, differentiation, and aging of the mouse intervertebral disc. Spine 34: 447-455.

8. Choi KS, Cohn MJ, Harfe BD (2008) Identification of nucleus pulposus precursor cells and notochordal remnants in the mouse: implications for disk degeneration and chordoma formation. Dev Dyn 237: 3953-3958.

9. Leung VY, Chan WC, Hung SC, Cheung KM, Chan D (2009) Matrix Remodeling During Intervertebral Disc Growth and Degeneration Detected by Multichromatic FAST Staining. J Histochem Cytochem 57: 249-256.

10. Nerurkar NL, Elliott DM, Mauck RL (2010) Mechanical design criteria for intervertebral disc tissue engineering. J Biomech 43: 1017-1030.

11. Hunter CJ, Matyas JR, Duncan NA (2003) The notochordal cell in the nucleus pulposus: a review in the context of tissue engineering. Tissue Eng 9: 667-677.

12. Minogue BM, Richardson SM, Zeef LA, Freemont AJ, Hoyland JA (2010) Characterization of the human nucleus pulposus cell phenotype and evaluation of novel marker gene expression to define adult stem cell differentiation. Arthritis and rheumatism 62: 3695-3705.

13. Minogue BM, Richardson SM, Zeef LA, Freemont AJ, Hoyland JA (2010) Transcriptional profiling of bovine intervertebral disc cells: implications for 
identification of normal and degenerate human intervertebral disc cell phenotypes. Arthritis research \& therapy 12: R22.

14. Sakai D, Nakai T, Mochida J, Alini M, Grad S (2009) Differential phenotype of intervertebral disc cells: microarray and immunohistochemical analysis of canine nucleus pulposus and anulus fibrosus. Spine (Phila Pa 1976) 34: 1448-1456.

15. Lee CR, Sakai D, Nakai T, Toyama K, Mochida J, et al. (2007) A phenotypic comparison of intervertebral disc and articular cartilage cells in the rat. Eur Spine J 16: 2174-2185.

16. Chen J, Yan W, Setton LA (2006) Molecular phenotypes of notochordal cells purified from immature nucleus pulposus. Eur Spine J 15 Suppl 15: 303-311.

17. Gilson A, Dreger M, Urban JP (2010) Differential expression level of cytokeratin 8 in cells of the bovine nucleus pulposus complicates the search for specific intervertebral disc cell markers. Arthritis research \& therapy 12: R24.

18. Kim JH, Deasy BM, Seo HY, Studer RK, Vo NV, et al. (2009) Differentiation of intervertebral notochordal cells through live automated cell imaging system in vitro. Spine 34: 2486-2493.

19. Guehring T, Wilde G, Sumner M, Grunhagen T, Karney GB, et al. (2009) Notochordal intervertebral disc cells: sensitivity to nutrient deprivation. Arthritis and rheumatism 60: 1026-1034.

20. Richardson SM, Walker RV, Parker S, Rhodes NP, Hunt JA, et al. (2006) Intervertebral disc cell-mediated mesenchymal stem cell differentiation. Stem Cells 24: 707-716.

21. Strassburg S, Richardson SM, Freemont AJ, Hoyland JA (2010) Co-culture induces mesenchymal stem cell differentiation and modulation of the degenerate human nucleus pulposus cell phenotype. Regenerative medicine 5: 701-711.

22. Korecki CL, Taboas JM, Tuan RS, Iatridis JC (2010) Notochordal cell conditioned medium stimulates mesenchymal stem cell differentiation toward a young nucleus pulposus phenotype. Stem cell research \& therapy 1: 18 .

23. Wei A, Chung SA, Tao H, Brisby H, Lin Z, et al. (2009) Differentiation of rodent bone marrow mesenchymal stem cells into intervertebral disc-like cells following coculture with rat disc tissue. Tissue engineering Part A 15: 2581-2595.

24. Yang Z, Huang CY, Candiotti KA, Zeng X, Yuan T, et al. (2011) Sox-9 facilitates differentiation of adipose tissue-derived stem cells into a chondrocyte-like phenotype in vitro. Journal of orthopaedic research : official publication of the Orthopaedic Research Society. 
25. Richardson SM, Curran JM, Chen R, Vaughan-Thomas A, Hunt JA, et al. (2006) The differentiation of bone marrow mesenchymal stem cells into chondrocyte-like cells on poly-l-lactic acid (PLLA) scaffolds. Biomaterials.

26. Risbud MV, Albert TJ, Guttapalli A, Vresilovic EJ, Hillibrand AS, et al. (2004) Differentiation of mesenchymal stem cells towards a nucleus pulposus-like phenotype in vitro: implications for cell-based transplantation therapy. Spine 29: 2627-2632.

27. Roughley P, Hoemann C, DesRosiers E, Mwale F, Antoniou J, et al. (2006) The potential of chitosan-based gels containing intervertebral disc cells for nucleus pulposus supplementation. Biomaterials 27: 388-396.

28. Hayes AJ, Benjamin M, Ralphs JR (2001) Extracellular matrix in development of the intervertebral disc. Matrix biology : journal of the International Society for Matrix Biology 20: 107-121.

29. Gruber HE, Mougeot JL, Hoelscher G, Ingram JA, Hanley EN, Jr. (2007) Microarray analysis of laser capture microdissected-anulus cells from the human intervertebral disc. Spine 32: 1181-1187.

30. Smits P, Lefebvre V (2003) Sox 5 and Sox6 are required for notochord extracellular matrix sheath formation, notochord cell survival and development of the nucleus pulposus of intervertebral discs. Development 130: 1135-1148.

31. Melrose J, Smith S, Knox S, Whitelock J (2002) Perlecan, the multidomain HS-proteoglycan of basement membranes, is a prominent pericellular component of ovine hypertrophic vertebral growth plate and cartilaginous endplate chondrocytes. Histochemistry and cell biology 118: 269-280.

32. Iatridis JC, Weidenbaum M, Setton LA, Mow VC (1996) Is the nucleus pulposus a solid or a fluid? Mechanical behaviors of the nucleus pulposus of the human intervertebral disc. Spine 21: 1174-1184.

33. Boxberger JI, Orlansky AS, Sen S, Elliott DM (2009) Reduced nucleus pulposus glycosaminoglycan content alters intervertebral disc dynamic viscoelastic mechanics. Journal of biomechanics 42: 1941-1946.

34. Mow VC, Guo XE (2002) Mechano-electrochemical properties of articular cartilage: their inhomogeneities and anisotropies. Annual review of biomedical engineering 4: 175-209.

35. Adams MA, Dolan P, McNally DS (2009) The internal mechanical functioning of intervertebral discs and articular cartilage, and its relevance to matrix biology. Matrix biology : journal of the International Society for Matrix Biology 28: 384-389.

36. Mwale F, Roughley P, Antoniou J (2004) Distinction between the extracellular 
matrix of the nucleus pulposus and hyaline cartilage: a requisite for tissue engineering of intervertebral disc. Eur Cell Mater 8: 58-63; discussion 63-54.

37. Maldonado BA, Oegema TR, Jr. (1992) Initial characterization of the metabolism of intervertebral disc cells encapsulated in microspheres. Journal of orthopaedic research : official publication of the Orthopaedic Research Society 10: 677-690.

38. Chiba K, Andersson GB, Masuda K, Thonar EJ (1997) Metabolism of the extracellular matrix formed by intervertebral disc cells cultured in alginate. Spine 22: 2885-2893.

39. Pfeiffer M, Griss P, Franke P, Bornscheuer C, Orth J, et al. (1994) Degeneration model of the porcine lumbar motion segment: effects of various intradiscal procedures. European spine journal : official publication of the European Spine Society, the European Spinal Deformity Society, and the European Section of the Cervical Spine Research Society 3: 8-16.

40. Nesti LJ, Li WJ, Shanti RM, Jiang YJ, Jackson W, et al. (2008) Intervertebral disc tissue engineering using a novel hyaluronic acid-nanofibrous scaffold (HANFS) amalgam. Tissue engineering Part A 14: 1527-1537.

41. Ganey T, Hutton WC, Moseley T, Hedrick M, Meisel HJ (2009) Intervertebral disc repair using adipose tissue-derived stem and regenerative cells: experiments in a canine model. Spine 34: 2297-2304.

42. Pfeiffer M, Boudriot U, Pfeiffer D, Ishaque N, Goetz W, et al. (2003) Intradiscal application of hyaluronic acid in the non-human primate lumbar spine: radiological results. European spine journal : official publication of the European Spine Society, the European Spinal Deformity Society, and the European Section of the Cervical Spine Research Society 12: 76-83.

43. Cloyd JM, Malhotra NR, Weng L, Chen W, Mauck RL, et al. (2007) Material properties in unconfined compression of human nucleus pulposus, injectable hyaluronic acid-based hydrogels and tissue engineering scaffolds. European spine journal : official publication of the European Spine Society, the European Spinal Deformity Society, and the European Section of the Cervical Spine Research Society 16: 1892-1898.

44. Revell PA, Damien E, Di Silvio L, Gurav N, Longinotti C, et al. (2007) Tissue engineered intervertebral disc repair in the pig using injectable polymers. Journal of materials science Materials in medicine 18: 303-308.

45. Nakashima S, Matsuyama Y, Takahashi K, Satoh T, Koie H, et al. (2009) Regeneration of intervertebral disc by the intradiscal application of cross-linked hyaluronate hydrogel and cross-linked chondroitin sulfate hydrogel in a rabbit model of intervertebral disc injury. Bio-medical materials 
and engineering 19: 421-429.

46. Li CH, Chik TK, Ngan AH, Chan SC, Shum DK, et al. (2011) Correlation between compositional and mechanical properties of human mesenchymal stem cell-collagen microspheres during chondrogenic differentiation. Tissue engineering Part A 17: 777-788.

47. Chan BP, Hui TY, Yeung CW, Li J, Mo I, et al. (2007) Self-assembled collagen-human mesenchymal stem cell microspheres for regenerative medicine. Biomaterials 28: 4652-4666.

48. Seguin CA, Grynpas MD, Pilliar RM, Waldman SD, Kandel RA (2004) Tissue engineered nucleus pulposus tissue formed on a porous calcium polyphosphate substrate. Spine 29: 1299-1306; discussion 1306-1297.

49. Discher DE, Janmey P, Wang YL (2005) Tissue cells feel and respond to the stiffness of their substrate. Science 310: 1139-1143.

50. Alini M, Li W, Markovic P, Aebi M, Spiro RC, et al. (2003) The potential and limitations of a cell-seeded collagen/hyaluronan scaffold to engineer an intervertebral disc-like matrix. Spine 28: 446-454; discussion 453.

51. Calderon L, Collin E, Velasco-Bayon D, Murphy M, O'Halloran D, et al. (2010) Type II collagen-hyaluronan hydrogel--a step towards a scaffold for intervertebral disc tissue engineering. European cells \& materials 20: 134-148.

52. Collin EC, Grad S, Zeugolis DI, Vinatier CS, Clouet JR, et al. (2011) An injectable vehicle for nucleus pulposus cell-based therapy. Biomaterials 32 : 2862-2870.

53. Abbushi A, Endres M, Cabraja M, Kroppenstedt SN, Thomale UW, et al. (2008) Regeneration of intervertebral disc tissue by resorbable cell-free polyglycolic acid-based implants in a rabbit model of disc degeneration. Spine 33: 1527-1532.

54. Endres M, Abbushi A, Thomale UW, Cabraja M, Kroppenstedt SN, et al. (2010) Intervertebral disc regeneration after implantation of a cell-free bioresorbable implant in a rabbit disc degeneration model. Biomaterials 31: 5836-5841.

55. Aladin DM, Cheung KM, Ngan AH, Chan D, Leung VY, et al. (2010) Nanostructure of collagen fibrils in human nucleus pulposus and its correlation with macroscale tissue mechanics. J Orthop Res 28: 497-502.

56. Zhu Y, Oganesian A, Keene DR, Sandell LJ (1999) Type IIA procollagen containing the cysteine-rich amino propeptide is deposited in the extracellular matrix of prechondrogenic tissue and binds to TGF-beta1 and BMP-2. The Journal of cell biology 144: 1069-1080.

57. Alexopoulos LG, Youn I, Bonaldo P, Guilak F (2009) Developmental and osteoarthritic changes in Col6a1-knockout mice: biomechanics of type VI 
collagen in the cartilage pericellular matrix. Arthritis and rheumatism 60: 771-779.

58. Guilak F, Alexopoulos LG, Upton ML, Youn I, Choi JB, et al. (2006) The pericellular matrix as a transducer of biomechanical and biochemical signals in articular cartilage. Annals of the New York Academy of Sciences 1068: 498-512.

59. Jakobsen RJ, Brown LL, Hutson TB, Fink DJ, Veis A (1983) Intermolecular interactions in collagen self-assembly as revealed by Fourier transform infrared spectroscopy. Science 220: 1288-1290.

60. Sakai D, Mochida J, Yamamoto Y, Nomura T, Okuma M, et al. (2003) Transplantation of mesenchymal stem cells embedded in Atelocollagen gel to the intervertebral disc: a potential therapeutic model for disc degeneration. Biomaterials 24: 3531-3541.

61. Chenite A, Chaput C, Wang D, Combes C, Buschmann MD, et al. (2000) Novel injectable neutral solutions of chitosan form biodegradable gels in situ. Biomaterials 21: 2155-2161.

62. Kisiday J, Jin M, Kurz B, Hung H, Semino C, et al. (2002) Self-assembling peptide hydrogel fosters chondrocyte extracellular matrix production and cell division: implications for cartilage tissue repair. Proceedings of the National Academy of Sciences of the United States of America 99: 9996-10001.

63. Chan SC, Gantenbein-Ritter B, Leung VY, Chan D, Cheung KM, et al. (2010) Cryopreserved intervertebral disc with injected bone marrow-derived stromal cells: a feasibility study using organ culture. Spine J 10: 486-496.

64. Henriksson HB, Svanvik T, Jonsson M, Hagman M, Horn M, et al. (2009) Transplantation of human mesenchymal stems cells into intervertebral discs in a xenogeneic porcine model. Spine (Phila Pa 1976) 34: 141-148.

65. Ifkovits JL, Burdick JA (2007) Review: photopolymerizable and degradable biomaterials for tissue engineering applications. Tissue engineering 13: 2369-2385.

66. Bron JL, van der Veen AJ, Helder MN, van Royen BJ, Smit TH (2010) Biomechanical and in vivo evaluation of experimental closure devices of the annulus fibrosus designed for a goat nucleus replacement model. European spine journal : official publication of the European Spine Society, the European Spinal Deformity Society, and the European Section of the Cervical Spine Research Society 19: 1347-1355.

67. Elliott DM, Setton LA (2001) Anisotropic and inhomogeneous tensile behavior of the human anulus fibrosus: experimental measurement and material model predictions. Journal of biomechanical engineering 123: 256-263. 
68. Cassidy JJ, Hiltner A, Baer E (1989) Hierarchical structure of the intervertebral disc. Connective tissue research 23: 75-88.

69. Nerurkar NL, Mauck RL, Elliott DM (2008) ISSLS prize winner: integrating theoretical and experimental methods for functional tissue engineering of the annulus fibrosus. Spine 33: 2691-2701.

70. Nerurkar NL, Baker BM, Sen S, Wible EE, Elliott DM, et al. (2009) Nanofibrous biologic laminates replicate the form and function of the annulus fibrosus. Nat Mater 8: 986-992.

71. Pezowicz CA, Robertson PA, Broom ND (2005) Intralamellar relationships within the collagenous architecture of the annulus fibrosus imaged in its fully hydrated state. Journal of anatomy 207: 299-312.

72. Schollum ML, Robertson PA, Broom ND (2009) A microstructural investigation of intervertebral disc lamellar connectivity: detailed analysis of the translamellar bridges. Journal of anatomy 214: 805-816.

73. Schollum ML, Robertson PA, Broom ND (2008) ISSLS prize winner: microstructure and mechanical disruption of the lumbar disc annulus: part I: a microscopic investigation of the translamellar bridging network. Spine 33: 2702-2710.

74. Smith LJ, Elliott DM (2011) Formation of lamellar cross bridges in the annulus fibrosus of the intervertebral disc is a consequence of vascular regression. Matrix biology : journal of the International Society for Matrix Biology.

75. Hamilton DJ, Pilliar RM, Waldman S, Kandel RA (2010) Effect of circumferential constraint on nucleus pulposus tissue in vitro. The spine journal : official journal of the North American Spine Society 10: 174-183.

76. Chang G, Kim HJ, Vunjak-Novakovic G, Kaplan DL, Kandel R (2010) Enhancing annulus fibrosus tissue formation in porous silk scaffolds. Journal of biomedical materials research Part A 92: 43-51.

77. Chang G, Kim HJ, Kaplan D, Vunjak-Novakovic G, Kandel RA (2007) Porous silk scaffolds can be used for tissue engineering annulus fibrosus. Eur Spine $\mathbf{J}$ 16: $1848-1857$.

78. Nerurkar NL, Elliott DM, Mauck RL (2007) Mechanics of oriented electrospun nanofibrous scaffolds for annulus fibrosus tissue engineering. Journal of orthopaedic research : official publication of the Orthopaedic Research Society 25: 1018-1028.

79. Yang L, Kandel RA, Chang G, Santerre JP (2009) Polar surface chemistry of nanofibrous polyurethane scaffold affects annulus fibrosus cell attachment and early matrix accumulation. Journal of biomedical materials research Part A 91: 1089-1099. 
80. Wilda H, Gough JE (2006) In vitro studies of annulus fibrosus disc cell attachment, differentiation and matrix production on PDLLA/45S5 Bioglass composite films. Biomaterials 27: 5220-5229.

81. Shao X, Hunter CJ (2007) Developing an alginate/chitosan hybrid fiber scaffold for annulus fibrosus cells. Journal of biomedical materials research Part A 82: 701-710.

82. Bowles RD, Williams RM, Zipfel WR, Bonassar LJ (2010) Self-assembly of aligned tissue-engineered annulus fibrosus and intervertebral disc composite via collagen gel contraction. Tissue engineering Part A 16: 1339-1348.

83. Sato M, Asazuma T, Ishihara M, Kikuchi T, Masuoka K, et al. (2003) An atelocollagen honeycomb-shaped scaffold with a membrane seal (ACHMS-scaffold) for the culture of annulus fibrosus cells from an intervertebral disc. Journal of biomedical materials research Part A 64: 248-256.

84. Saad L, Spector M (2004) Effects of collagen type on the behavior of adult canine annulus fibrosus cells in collagen-glycosaminoglycan scaffolds. Journal of biomedical materials research Part A 71: 233-241.

85. Johnson WE, Wootton A, El Haj A, Eisenstein SM, Curtis AS, et al. (2006) Topographical guidance of intervertebral disc cell growth in vitro: towards the development of tissue repair strategies for the anulus fibrosus. European spine journal : official publication of the European Spine Society, the European Spinal Deformity Society, and the European Section of the Cervical Spine Research Society 15 Suppl 3: S389-396.

86. Nerurkar NL, Sen S, Huang AH, Elliott DM, Mauck RL (2010) Engineered disc-like angle-ply structures for intervertebral disc replacement. Spine (Phila Pa 1976) 35: 867-873.

87. Attia M, Santerre JP, Kandel RA (2011) The response of annulus fibrosus cell to fibronectin-coated nanofibrous polyurethane-anionic dihydroxyoligomer scaffolds. Biomaterials 32: 450-460.

88. Wade KR, Robertson PA, Broom ND (2011) A fresh look at the nucleus-endplate region: new evidence for significant structural integration. European spine journal : official publication of the European Spine Society, the European Spinal Deformity Society, and the European Section of the Cervical Spine Research Society.

89. Hamilton DJ, Seguin CA, Wang J, Pilliar RM, Kandel RA (2006) Formation of a nucleus pulposus-cartilage endplate construct in vitro. Biomaterials 27: 397-405.

90. Arana CJ, Diamandis EP, Kandel RA (2010) Cartilage tissue enhances 
proteoglycan retention by nucleus pulposus cells in vitro. Arthritis and rheumatism 62: 3395-3403.

91. Waldman SD, Grynpas MD, Pilliar RM, Kandel RA (2002) Characterization of cartilagenous tissue formed on calcium polyphosphate substrates in vitro. Journal of biomedical materials research 62: 323-330.

92. Rodriguez AG, Slichter CK, Acosta FL, Rodriguez-Soto AE, Burghardt AJ, et al. (2011) Human Disc Nucleus Properties and Vertebral Endplate Permeability. Spine (Phila Pa 1976).

93. Benneker LM, Heini PF, Alini M, Anderson SE, Ito K (2005) 2004 Young Investigator Award Winner: vertebral endplate marrow contact channel occlusions and intervertebral disc degeneration. Spine 30: 167-173.

94. Lee CR, Iatridis JC, Poveda L, Alini M (2006) In vitro organ culture of the bovine intervertebral disc: effects of vertebral endplate and potential for mechanobiology studies. Spine 31: 515-522.

95. Gantenbein B, Grunhagen T, Lee CR, van Donkelaar CC, Alini M, et al. (2006) An in vitro organ culturing system for intervertebral disc explants with vertebral endplates: a feasibility study with ovine caudal discs. Spine 31: 2665-2673.

96. MacLean JJ, Owen JP, Iatridis JC (2007) Role of endplates in contributing to compression behaviors of motion segments and intervertebral discs. Journal of biomechanics 40: 55-63.

97. Luk KD, Ruan DK, Lu DS, Fei ZQ (2003) Fresh frozen intervertebral disc allografting in a bipedal animal model. Spine 28: 864-869; discussion 870 .

98. Mizuno H, Roy AK, Zaporojan V, Vacanti CA, Ueda M, et al. (2006) Biomechanical and biochemical characterization of composite tissue-engineered intervertebral discs. Biomaterials 27: 362-370.

99. Wan Y, Feng G, Shen FH, Laurencin CT, Li X (2008) Biphasic scaffold for annulus fibrosus tissue regeneration. Biomaterials 29: 643-652.

100. Cheng HW, Luk KD, Cheung KM, Chan BP (2011) In vitro generation of an osteochondral interface from mesenchymal stem cell-collagen microspheres. Biomaterials 32: 1526-1535.

101. Liebscher T, Haefeli M, Wuertz K, Nerlich AG, Boos N (2011) Age-related variation in cell density of human lumbar intervertebral disc. Spine 36: 153-159.

102. Shirazi-Adl A, Taheri M, Urban JP (2010) Analysis of cell viability in intervertebral disc: Effect of endplate permeability on cell population. Journal of biomechanics 43: 1330-1336.

103. Nishimura I, Garrell RL, Hedrick M, Iida K, Osher S, et al. (2003) Precursor 
tissue analogs as a tissue-engineering strategy. Tissue engineering 9 Suppl 1: S77-89.

104. Illien-Junger S, Gantenbein-Ritter B, Grad S, Lezuo P, Ferguson SJ, et al. (2010) The combined effects of limited nutrition and high-frequency loading on intervertebral discs with endplates. Spine 35: 1744-1752.

105. Ferguson SJ, Ito K, Nolte LP (2004) Fluid flow and convective transport of solutes within the intervertebral disc. Journal of biomechanics 37: 213-221.

106. Arun R, Freeman BJ, Scammell BE, McNally DS, Cox E, et al. (2009) 2009 ISSLS Prize Winner: What influence does sustained mechanical load have on diffusion in the human intervertebral disc?: an in vivo study using serial postcontrast magnetic resonance imaging. Spine 34: 2324-2337.

107. Fernando HN, Czamanski J, Yuan TY, Gu W, Salahadin A, et al. (2011) Mechanical loading affects the energy metabolism of intervertebral disc cells. Journal of orthopaedic research : official publication of the Orthopaedic Research Society.

108. Korecki CL, Kuo CK, Tuan RS, Iatridis JC (2009) Intervertebral disc cell response to dynamic compression is age and frequency dependent. Journal of orthopaedic research : official publication of the Orthopaedic Research Society 27: 800-806.

109. Korecki CL, MacLean JJ, Iatridis JC (2008) Dynamic compression effects on intervertebral disc mechanics and biology. Spine 33: 1403-1409.

110. Wang DL, Jiang SD, Dai LY (2007) Biologic response of the intervertebral disc to static and dynamic compression in vitro. Spine 32: 2521-2528. 